\title{
Systemic venous oxygen saturation after the Norwood procedure and childhood neurodevelopmental outcome
}

\author{
George M. Hoffman, MD, a,d,f,g Kathleen A. Mussatto, BSN, b,c Cheryl L. Brosig, PhD, e,g Nancy S. Ghanayem, MD, d,g \\ Ndidiamaka Musa, MD, ${ }^{\mathrm{d}, \mathrm{g}}$ Raymond T. Fedderly, MD, ${ }^{\mathrm{b}, \mathrm{g}}$ Robert D. B. Jaquiss, MD, ${ }^{\mathrm{c}, \mathrm{h}}$ and James S. Tweddell, MD ${ }^{\mathrm{c}, \mathrm{g}, \mathrm{h}}$
}

From the Departments of Pediatric Anesthesiology, ${ }^{\mathrm{a}}$ Cardiology, ${ }^{\mathrm{b}}$ Cardiovascular Surgery, ${ }^{\mathrm{c}}$ Critical Care Medicine, ${ }^{\mathrm{d}}$ and Pediatric Psychology, ${ }^{\mathrm{e}}$ Children's Hospital of Wisconsin, and the Departments of Anesthesiology, ${ }^{\mathrm{f}}$ Pediatrics, ${ }^{\mathrm{g}}$ and Cardiothoracic Surgery, ${ }^{\mathrm{h}}$ Medical College of Wisconsin, Milwaukee, Wis.

Presented in part at the annual meeting of the American Society of Anesthesiologists, Las Vegas, Nevada, October 2004.

Received for publication May 12, 2005; revisions received June 16, 2005; accepted for publication June 28, 2005.

Address for reprints: George M. Hoffman, MD, Anesthesiology and Pediatrics, Children's Hospital of Wisconsin, $9000 \mathrm{~W}$ Wisconsin Ave, Milwaukee, WI 53226 (Email: ghoffman@mcw.edu).

J Thorac Cardiovasc Surg 2005;130:1094-100 $0022-5223 / \$ 30.00$

Copyright $\odot 2005$ by The American Association for Thoracic Surgery

doi:10.1016/j.jtcvs.2005.06.029
Objective: Neonates with hypoplastic left heart syndrome have impaired systemic oxygen delivery and also have a high risk of hypoxic ischemic brain injury with resultant neurodevelopmental impairment. We hypothesized that decreased postoperative oxygen delivery, as measured on the basis of systemic venous oxyhemoglobin saturation, would be related to persistent neurodevelopmental abnormality assessed in childhood.

Methods: Early perioperative hemodynamic data, prospectively acquired from neonates undergoing staged palliation of hypoplastic left heart syndrome by using deep hypothermic circulatory arrest with uniform perioperative management, were tested for relationship to later neurodevelopmental outcome assessed at age 4 years.

Results: Complete hemodynamic and neurodevelopmental data were available in 13 patients aged $7 \pm 8$ days at the time of the Norwood procedure and aged $4.5 \pm 0.7$ years at follow-up assessment. The subjects scored significantly below the population mean for motor, visual-motor integration, and composite neurodevelopmental outcomes. The $5(38 \%)$ patients with abnormal outcomes had significantly lower postoperative systemic venous oxygen saturation values than those with normal outcomes $(46 \% \pm 8 \%$ vs $56 \% \pm 6 \%, P=.024)$. Standard hemodynamic parameters did not differentiate patient outcomes. The risk of abnormal outcome increased with increasing time at a systemic venous oxygen saturation of less than $40 \%(P<.001)$. A multivariate model of deep hypothermic circulatory arrest time, systemic venous oxygen saturation, blood pressure, and carbon dioxide tension accounted for $79 \%$ of the observed variance $(P<.001)$.

Conclusions: Decreased systemic oxygen delivery in the neonatal postoperative period is associated with hypoxic-ischemic brain injury and childhood neurodevelopmental abnormality. Measures of systemic oxygen delivery should be used to guide perioperative strategies to reduce the risk of hypoxic-ischemic brain injury.

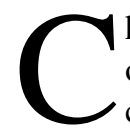
hildren with congenital heart disease are at increased risk for neurodevelopmental impairment. Causes of reduced neurodevelopmental outcome include genetic factors, abnormalities of the aortic arch (including hypoplastic left heart syndrome [HLHS]), ${ }^{1}$ hypoxic-ischemic injury, genetic predisposition, ${ }^{2}$ and complex environmental factors. ${ }^{3-5}$ Perioperative events are commonly identified as potential causes of hypoxic-ischemic injury, ${ }^{6-8}$ particularly prolonged periods of circulatory $\operatorname{arrest}^{9}$ and other cardiopulmonary bypass (CPB) support strategies that reduce oxygen delivery, such as anemia ${ }^{10}$ and alkalosis. ${ }^{11,12}$ However, intraoperative factors do not adequately explain all adverse outcomes. ${ }^{5,8,13-15}$

We have previously identified a higher risk of reduced systemic oxygen delivery by using continuous systemic venous oxygen saturation $\left(\mathrm{SvO}_{2}\right)$ monitoring and reduced cerebral oxygen saturation by using near-infrared spectroscopy (NIRS) in the early postoperative period in neonates undergoing the Norwood procedure. ${ }^{15-17}$ 
Positing that impaired neurodevelopmental outcome might be a late manifestation of postoperative hypoxic-ischemic injury, we examined the relationship between neonatal perioperative hemodynamics and school-age neurodevelopmental outcome in survivors of staged palliation of HLHS. The primary hypothesis was that inadequate postoperative oxygen delivery, assessed by measuring $\mathrm{SvO}_{2}$ after neonatal stage 1 repair, would be a predictor of poor neurocognitive function at age 4 years.

\section{Methods \\ Patients}

All neonates undergoing staged palliation of HLHS since 1996 have had neonatal perioperative hemodynamics maintained in a database. All survivors have been offered enrollment in a neurodevelopmental outcome study after achieving acceptable hemodynamics for completion of the Fontan procedure and attaining a minimum age of 3.5 years. Because perioperative management strategies have evolved over the past decade in ways that might affect hypoxic-ischemic injury, we limited this analysis to patients who had undergone a modified Norwood procedure for stage 1 palliation (S1P) of HLHS or a single-ventricle variant with deep hypothermic circulatory arrest (DHCA) after achievement of synthetic opioid-based perioperative anesthesia, as previously described. ${ }^{16,18}$ Cooling to $18^{\circ} \mathrm{C}$ to $20^{\circ} \mathrm{C}$ was achieved with a highflow modified $\mathrm{pH}$-stat strategy with a minimum cooling time of 25 minutes, ${ }^{19}$ followed by a shift to alpha-stat blood gas management just before circulatory arrest. ${ }^{20}$ All patients had continuous superior vena caval (SVC) $\mathrm{SvO}_{2}$ monitoring to guide an aggressive inodilator strategy with an $\mathrm{SvO}_{2}$ target of $50 \% .^{16,18,21}$

Of 43 sequential patients who had S1P performed from 1996 through 1999 by using this standardized perioperative management strategy, 30 were alive at the time of this cross-sectional study. Three were excluded because of coexisting anomalies or extreme prematurity thought to independently affect neurodevelopmental performance. Parents of the 27 eligible patients were invited to participate in this study. Responses were obtained from 21 families, and neurodevelopmental testing was completed in 13. Distance greater than 100 miles from the testing center was the primary reason for nonresponse or noncompletion of testing. All patients who had completed neurodevelopmental assessment by September 2004 were included in this analysis.

\section{Neurodevelopment Assessment}

A comprehensive test battery was administered by a single developmental psychologist (CLB) under controlled conditions and with institutional review board approval. Individual tests included in this analysis were the McCarthy Scale of Children's AbilitiesMotor and the McCarthy Scale of Children's Abilities-General Cognitive, the Beery Test of Visual-Motor Integration, and Achenbach's Child Behavior Checklist. These 4 individual test scores were normalized to an average score of 100 and standard deviation (SD) of 15 and summed to generate a composite outcome score. These tests measure a range of basic and higher-level integrative motor, cognitive, and psychosocial skills, representing areas of function that are at risk for impairment in children with complex congenital heart disease. ${ }^{9,11,22,23}$ A cutoff of greater than -2 SD from the population mean was used to classify test results as abnormal.

\section{Hemodynamic Assessment}

Perioperative hemodynamic indices were recorded prospectively for the first 48 hours after neonatal S1P, including arterial oxygen saturation $\left(\mathrm{SaO}_{2}\right), \mathrm{SVC} \mathrm{SvO}_{2}$, mean arterial blood pressure (MABP), central venous pressure (CVP), heart rate (HR), hemoglobin concentration, $\mathrm{PaCO}_{2}$, base excess, and $\mathrm{pH}$ and derived parameters of arteriovenous oxygen saturation difference $\left(\mathrm{Sa}-\mathrm{VO}_{2}\right)$ and arteriovenous oxygen content difference $\left(\mathrm{Ca}-\mathrm{-vO}_{2}\right)$. Intraoperative parameters included duration of support (DHCA time and CPB time) and use of phenoxybenzamine.

\section{Statistical Analysis}

Data were expressed as means \pm SD for descriptive statistics and as means \pm standard error for estimated statistics, with $95 \%$ confidence intervals as appropriate. The differences in early hemodynamic parameters between patients with normal or abnormal outcomes were assessed by means of one-way analysis of variance for mean values or by using the Fisher exact test for proportions. The relationship between late outcome and early hemodynamic parameters was assessed by means of multivariate, generalized, least-squares (GLS) time-series regression with correction for autocorrelation and by means of repeated-measures analysis of variance for nonlinear models. Continuous values for hemodynamic parameters were divided into clinically appropriate strata to assess the risk of abnormal outcome at key thresholds by means of binomial odds ratios and time-series logistic regression. The cutoff for significance was a $P$ value of less than .05 after multiple comparison correction with the Tukey honestly significant difference or the Bonferroni method when applicable. All calculations were performed with Stata Version 8 (Stata Corporation, College Station, Tex).

\section{Results}

Complete hemodynamic and outcome assessment was available in 13 patients for this analysis. The cohort had S1P at $7 \pm 8$ days (median, 4 days) at a weight of $3.3 \pm 0.7 \mathrm{~kg}$. The duration of DHCA was $62 \pm 8$ minutes, and the duration of CPB was $128 \pm 50$ minutes. The postoperative hemodynamic profile was analyzed from a complete set of 624 hours of data. This profile showed a mean $\mathrm{SaO}_{2}$ of $77 \%$ $\pm 5 \%, \mathrm{SvO}_{2}$ of $52 \% \pm 11 \%, \mathrm{Sa}-\mathrm{vO}_{2}$ of $25 \% \pm 9 \%$, hemoglobin concentration of $15 \pm 1.5 \mathrm{~g} / 100 \mathrm{~mL}, \mathrm{Ca}-\mathrm{vO}_{2}$ of 4.9 $\pm 1.8 \mathrm{~mL} / \mathrm{dL}, \mathrm{MABP}$ of $52 \pm 5 \mathrm{~mm} \mathrm{Hg}, \mathrm{CVP}$ of $11 \pm 3$ $\mathrm{mm} \mathrm{Hg}, \mathrm{HR}$ of $168 \pm 18 \mathrm{~min}^{-1}$, base excess of $3 \pm 4$ $\mathrm{mEq} / \mathrm{L}$, and $\mathrm{PaCO}_{2}$ of $41 \pm 6 \mathrm{~mm} \mathrm{Hg}$. No patients required postoperative mechanical circulatory support.

At the time of neurodevelopment assessment, patients were $4.5 \pm 0.7$ years of age and ambulatory after completion of the Fontan operation. The study population performed below the population mean on a number of domains. The McCarthy Scale of Children's Abilities-Motor (42 \pm 10 vs $50 \pm 10, P=.01)$, Beery Test of Visual-motor Integration $(87 \pm 14$ vs $100 \pm 15, P=.006)$, and composite 
TABLE 1. Summary of neurodevelopmental assessment in the cohort and normal populations

\begin{tabular}{lcccc}
\hline Outcome & Subject score & Population score & $\begin{array}{c}\text { No. (\%) } \\
\text { abnormal }\end{array}$ & $\boldsymbol{P}$ value \\
\hline MSOCAG & $90 \pm 27$ & $100 \pm 15$ & $3(23 \%)$ & .28 \\
MSOCAM & $42 \pm 10$ & $50 \pm 10$ & $1(8 \%)$ & .01 \\
VMI & $87 \pm 14$ & $100 \pm 15$ & $2(15 \%)$ & .006 \\
CBCL & $54 \pm 10$ & $50 \pm 10$ & $3(23 \%)$ & .18 \\
Composite & $352 \pm 66$ & $400 \pm 50$ & $4(31 \%)$ & .03
\end{tabular}

Values are presented as means \pm SD where shown. MSOCAG, McCarthy Scale of Children's Abilities-General Cognitive; MSOCAM, McCarthy Scale of Children's Abilities-Motor; VMI, Beery Test of Visual-Motor Integration; $C B C L$, Achenbach's Child Behavior Checklist.

scores (352 \pm 66 vs $400 \pm 60, P=.03)$ were significantly below normal in the cohort. Five (38\%; 95\% confidence interval, 14\%-68\%) patients had at least one clearly abnormal score at least 2 SDs below the mean (Table 1).

The patients with any abnormal outcome $(\mathrm{n}=5)$ were grouped to compare their early hemodynamic parameters with those of patients without abnormal outcomes $(n=8)$. Univariate analysis of hemodynamics showed no significant differences for MABP $(51 \pm 5$ vs $54 \pm 3 \mathrm{~mm} \mathrm{Hg}, P=.23)$, $\mathrm{SaO}_{2}(78 \% \pm 3 \%$ vs $74 \% \pm 3 \%, P=.07), \mathrm{PaCO}_{2}(41 \pm 3$ vs $39 \pm 5 \mathrm{~mm} \mathrm{Hg}, P=.36)$, DHCA time ( $60 \pm 6$ vs $67 \pm$ 12 minutes, $P=.18)$, CPB time $(118 \pm 21$ vs $150 \pm 27$ minutes, $P=.33$ ), or phenoxybenzamine administration $(8 / 8$ vs $3 / 5, P=.14)$ between patients with normal and abnormal outcomes. However, $\mathrm{SvO}_{2}$ was significantly lower in patients with abnormal outcomes $(56 \% \pm 6 \%$ vs $46 \% \pm$ $8 \%, P=.024)$. Low $\mathrm{SvO}_{2}$ was present regardless of abnormal outcome assessed (Table 2).

By treating each hour of hemodynamic data as a separate independent "dose," the additive risk of $\mathrm{SvO}_{2}$ on outcome was assessed in a case-control model. Each hour at an $\mathrm{SvO}_{2}$ of $40 \%$ or less increased the risk of abnormal composite outcome (risk ratio, $4.7 ; 95 \%$ confidence interval, 3.3-6.5; $P$ $<.001$ ). A clear dose-response effect was present for time at progressively low $\mathrm{SvO}_{2}$ (Table 3).
TABLE 3. The number of hours spent at different $\mathrm{Sv}_{2}$ values and relative risk of abnormal composite outcome

\begin{tabular}{lcclc}
\hline $\mathbf{S v 0}_{\mathbf{2}}(\%)$ & Total (h) & Cases (h) & RR (95\% Cl) & $\begin{array}{c}\text { Exact } \\
\boldsymbol{P} \text { value }\end{array}$ \\
\hline$\leq 30 \%$ & 23 & 14 & $8.5(4.2-17.1)$ & $<.001$ \\
$31 \%-40 \%$ & 67 & 28 & $5.8(2.9-11.6)$ & $<.001$ \\
$41 \%-50 \%$ & 153 & 15 & $1.4(0.6-3.0)$ & .523 \\
$50 \%-60 \%$ & 255 & 30 & $1.6(0.8-3.3)$ & .21 \\
$>60 \%$ & 125 & 9 & Reference &
\end{tabular}

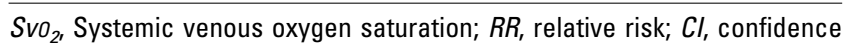
interval.

Time-series analysis of early hemodynamic parameter patterns showed more subtle influences on late outcomes. In this analysis systemic oxygen delivery, as measured on the basis of $\mathrm{SvO}_{2}, \mathrm{SaO}_{2}$, and $\mathrm{Sa}_{-} \mathrm{vo}_{2}$, was significantly lower in patients with abnormal outcomes (Figure 1). Borderline differences were observed for $\mathrm{PaCO}_{2}$ and MABP (Figure 2). There were no significant differences for hemoglobin concentration, HR, CVP, base excess, or pH (Table 4). Multivariable analysis revealed that the composite outcome score was most powerfully related to circulatory arrest time of greater than 60 minutes, $\mathrm{SvO}_{2}, \mathrm{MABP}$, and $\mathrm{PaCO}_{2}$ in a model that explained $79 \%$ of the variance in outcome (Table 5). This multivariate predictive model demonstrated a significant nonlinear relationship of $\mathrm{SvO}_{2}$ to all outcome measures, with an apparent break point at an $\mathrm{SvO}_{2}$ of less than $40 \%$. The model of composite outcome score versus $\mathrm{SvO}_{2}$ is shown in Figure 3. Multivariate modeling revealed significant interaction between terms and nonlinear modulation of the $\mathrm{SvO}_{2}$ effect by $\mathrm{PaCO}_{2}$ and prolonged DHCA time (Figures 4 and 5).

\section{Discussion}

The main conclusion of this analysis is that systemic oxygen delivery, as assessed on the basis of $\mathrm{SVC} \mathrm{SvO}_{2}$ in the early postoperative period after the Norwood operation, was a significant contributor to neurological function, as assessed

TABLE 2. Postoperative $\mathrm{Svo}_{2}$ compared according to neurodevelopmental test result

\begin{tabular}{|c|c|c|c|c|}
\hline Outcome & $\begin{array}{l}\text { No. of subjects } \\
\text { abnormal }\end{array}$ & $\begin{array}{l}\mathrm{SvO}_{2} \text { in subjects } \\
\text { with normal outcomes }\end{array}$ & $\begin{array}{c}\mathrm{Svo}_{2} \text { in subjects } \\
\text { with abnormal outcomes }\end{array}$ & $P$ value \\
\hline MSOCAG & 3 & $54 \pm 7$ & $45 \pm 11$ & .08 \\
\hline MSOCAM & 1 & $54 \pm 7$ & 34 & .014 \\
\hline VMI & 2 & $54 \pm 6$ & $39 \pm 9$ & .015 \\
\hline CBCL & 2 & $54 \pm 7$ & $41 \pm 11$ & .041 \\
\hline Composite & 4 & $55 \pm 6$ & $45 \pm 9$ & .034 \\
\hline Any & 5 & $55 \pm 6$ & $46 \pm 8$ & .024 \\
\hline
\end{tabular}

Values are presented as means \pm standard deviation where shown. Svo ${ }_{2}$, Systemic venous oxygen saturation; MSOCAG, McCarthy Scale of Children's Abilities-General Cognitive; MSOCAM, McCarthy Scale of Children's Abilities-Motor; VMI, Beery Test of Visual-Motor Integration; CBCL, Achenbach's Child Behavior Checklist. 


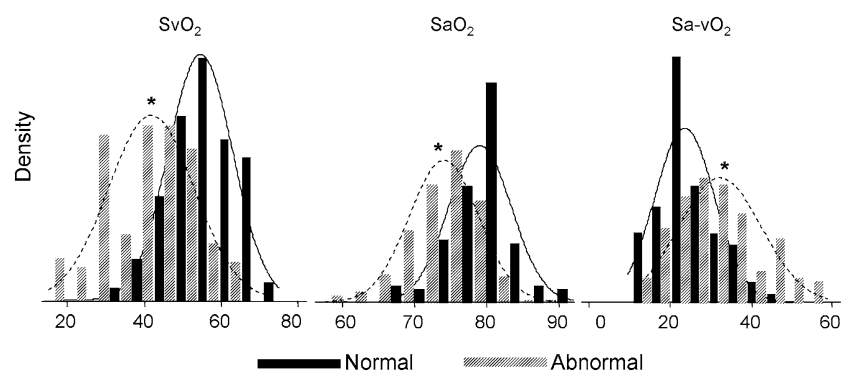

Figure 1. Distributions of systemic venous oxygen saturation $\left(\mathrm{SvO}_{2}\right)$, arterial oxygen saturation $\left(\mathrm{SaO}_{2}\right)$, and arteriovenous oxygen saturation difference $\left(\mathrm{Sa}_{\mathrm{aO}}\right)$ over the first 48 postoperative hours in the 2 subgroups of patients. Patients with abnormal outcomes had lower systemic venous oxygen saturation ${ }^{*} P=$ $.012)$, arterial oxygen saturation $\left({ }^{*} P=.036\right)$, and higher arteriovenous oxygen saturation difference $\left({ }^{*} P=.039\right)$ values.

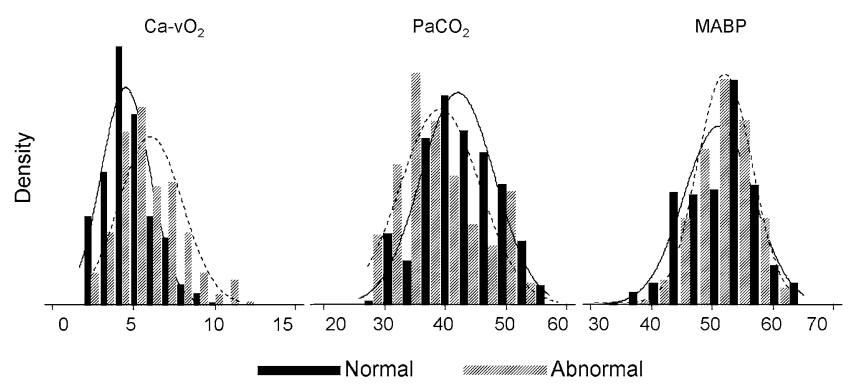

Figure 2. Forty-eight-hour distributions of arteriovenous oxygen content difference $\left(\mathrm{Ca}-\mathrm{vO}_{2}\right), \mathrm{PaCO}_{2}$, and mean arterial blood pressure (MABP) were not different in patients with normal versus abnormal outcomes.
TABLE 5. Multivariable regression on composite outcome score

\begin{tabular}{lrccc}
\hline \multicolumn{1}{c}{ Variable } & Coefficient & Variance & $\boldsymbol{P}$ value & Partial Correlation \\
\hline DHCA (>60 min) & $-99 \pm 28$ & $26 \%$ & .021 & -0.51 \\
$\mathrm{SvO}_{2}$ & $5.0 \pm 1.6$ & $22 \%$ & .031 & 0.42 \\
$\mathrm{MABP}_{\mathrm{PaCO}_{2}}$ & $8.3 \pm 3.4$ & $21 \%$ & .031 & 0.38 \\
Model $^{2}$ & $8.8 \pm 4.4$ & $10 \%$ & .011 & 0.38 \\
\end{tabular}

$D H C A$, Deep hypothermic circulatory arrest; $S_{20_{2}}$, systemic venous oxygen saturation; $M A B P$, mean arterial blood pressure.

at relatively late follow-up. In this population of children treated at a single institution during a time of little variation in intraoperative and postoperative management, 4 factors (prolonged circulatory arrest time, $\mathrm{SvO}_{2}, \mathrm{MABP}$, and $\mathrm{PaCO}_{2}$ ) accounted for almost $80 \%$ of the variance in a composite neurodevelopmental outcome score. Thus this study provides coherent data consistent with the hypothesis that perioperative systemic oxygen delivery can influence neurological function significantly enough to affect long-term development. Although a causal relationship is not proved in this observational study, known pathophysiologic processes link hypoxic-ischemic brain injury with neurodevelopmental delay, and thus management strategies that target improved systemic oxygen delivery might not only improve survival $^{18,21}$ but likely also neurologic function., 5,24

The strength of the association between factors related to hypoxic injury and late outcome in this relatively small study results partly from the wide range of performance and frequency of poor performance observed in the subjects' neurodevelopmental testing. The expected probability of 5 abnormal test results in this sample size would be no greater than $1 \%$ if drawn from a normal sample. The possibility of selection bias in subjects' participation in neurodevelop-

TABLE 4. Forty-eight-hour hemodynamic profile in patients with normal versus abnormal outcomes

\begin{tabular}{|c|c|c|c|}
\hline Parameter & $\begin{array}{l}\text { Normal outcome } \\
\quad(n=8)\end{array}$ & $\begin{array}{l}\text { Any abnormal outcome } \\
\qquad(n=5)\end{array}$ & $P$ value \\
\hline $\mathrm{SvO}_{2}(\%)$ & $55 \pm 2(51-60)$ & $46 \pm 3(40-52)$ & .012 \\
\hline $\mathrm{SaO}_{2}(\%)$ & $78 \pm 1(76-80)$ & $75 \pm 1(72-77)$ & .036 \\
\hline $\mathrm{Sa}^{-\mathrm{VO}_{2}}(\%)$ & $23 \pm 2(19-26)$ & $29 \pm 2(24-33)$ & .039 \\
\hline Ca- $\mathrm{vo}_{2}(\mathrm{~mL} / \mathrm{dL})$ & $4.4 \pm 0.4(3.6-5.2)$ & $5.6 \pm 0.5(4.6-6.6)$ & .086 \\
\hline POB $\left(\mathrm{mg} \cdot \mathrm{kg}^{-1} \cdot \mathrm{d}^{-1}\right)$ & $0.17 \pm 0.04(0.10-0.24)$ & $0.08 \pm 0.05(0-0.17)$ & .14 \\
\hline $\mathrm{pH}$ & $7.42 \pm 0.01(7.39-7.45)$ & $7.45 \pm 0.01(7.42-7.49)$ & .17 \\
\hline $\mathrm{PaCO}_{2}(\mathrm{~mm} \mathrm{Hg})$ & $42 \pm 1(39-45)$ & $39 \pm 2(35-43)$ & .17 \\
\hline MABP $(\mathrm{mm} \mathrm{Hg})$ & $51 \pm 1(48-53)$ & $54 \pm 2(50-57)$ & .18 \\
\hline $\mathrm{Hb}(\mathrm{g} / \mathrm{dL})$ & $14.7 \pm 0.4(14.0-15.4)$ & $14.3 \pm 0.5(13.4-15.1)$ & .45 \\
\hline CVP (mm Hg) & $11.2 \pm 1.0(9.2-13.0)$ & $10.5 \pm 1.2(8.1-12.9)$ & .67 \\
\hline $\mathrm{HR}(1 / \mathrm{min})$ & $167 \pm 4(159-176)$ & $168 \pm 5(157-179)$ & .89 \\
\hline
\end{tabular}

Values are presented as means \pm standard error (95\% confidence interval) where shown. $\mathrm{SvO}_{2}$, Systemic venous oxygen saturation; $\mathrm{SaO}_{2}$, arterial oxygen saturation; $\mathrm{Sa}_{-} \mathrm{VO}_{2}$, arteriovenous oxygen saturation difference; $\mathrm{Ca}-\mathrm{VO}_{2}$, arteriovenous oxygen content difference; $P O B$, phenoxybenzamine; MABP, mean arterial blood pressure; $H b$, hemoglobin; $C V P$, central venous pressure; $H R$, heart rate. 


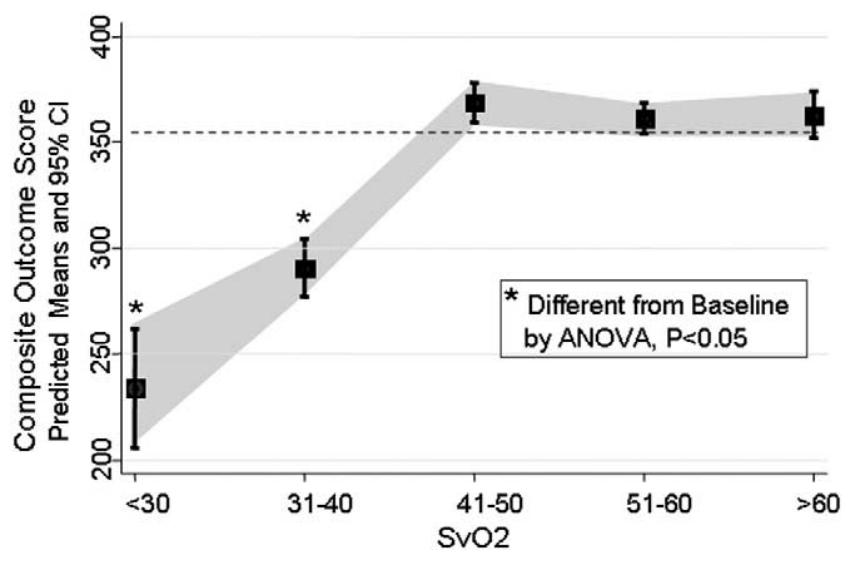

Figure 3. The composite outcome score was modeled as a function of hourly hemodynamic data and cardiopulmonary bypass parameters (arterial oxygen saturation, systemic venous oxygen saturation $\left[\mathrm{SvO}_{2}\right]$, mean arterial blood pressure, central venous pressure, $\mathrm{PaCO}_{2}$, cardiopulmonary bypass time, and deep hypothermic circulatory arrest time). The model reveals the effect of systemic venous oxygen saturation on outcome, with a break point of a systemic venous oxygen saturation of less than $40 \%$ ( $P$ $<.05$, analysis of variance [ANOVA]). Adjustment for other parameters did not change the main model effect but increased the power (from $R^{2}=0.49$ to 0.63 ). $\mathbf{C l}$, Confidence interval.

mental assessment might contribute to the incidence of abnormality, but this high incidence is consistent with other reports. ${ }^{1,3,5,6,23}$ Although the absolute risk of abnormal outcome could only be estimated by a prospective study with complete ascertainment, the association between low postoperative $\mathrm{SvO}_{2}$ and poor outcome is not likely to be influenced by ascertainment bias in this sample population. The perioperative demographic and hemodynamic profile of the tested cohort was not different from that of the entire contemporaneously operated S1P population $(n=43$, data not shown).

The postoperative hemodynamic parameter most variable in this patient population was $\mathrm{SvO}_{2}$, but the overall hemodynamic profiles were otherwise distinctly unremarkable. The children with poorer outcomes were specifically not hypotensive, acidotic, or subject to extreme arterial hypoxemia, conditions that have been associated with early postoperative changes on magnetic resonance imaging. ${ }^{6,25}$ They received similar levels of inotropic support and had no requirement for cardiopulmonary resuscitation. The results of their management strategy simply failed to achieve the target $\mathrm{SvO}_{2}$ for a greater period of time. Postoperative mechanical circulatory support was not used on an emergency basis or electively to maintain organ perfusion. ${ }^{26}$

Because standard monitoring modalities did not discriminate patients with abnormal outcomes, we believe that

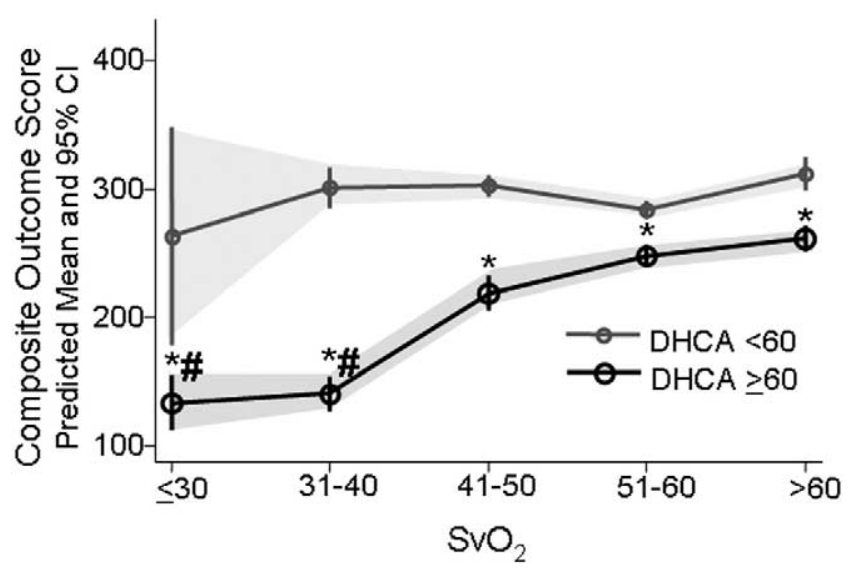

Figure 4. The interaction between prolonged deep hypothermic circulatory arrest (DHCA) time and postoperative hemodynamics is shown in a predictive model. Patients undergoing prolonged deep hypothermic circulatory arrest had significantly lower composite outcome scores at low systemic venous oxygen saturation $\left(\mathrm{Svo}_{2} ; \# P<.05\right.$, analysis of variance post-tests), and prolonged deep hypothermic circulatory arrest reduced neurodevelopmental outcome for any systemic venous oxygen saturation $\left(^{*} P<.05\right.$, analysis of variance). Adjustment for other parameters did not change the main or interaction model effects but increased the power (from $\boldsymbol{R}^{2}=\mathbf{0 . 4 9}$ to $\mathbf{0 . 5 8}$ ). $\mathrm{Cl}$, Confidence interval.

measurements of organ oxygen economy by means of $\mathrm{SvO}_{2}$ or potentially NIRS should be used to characterize the circulatory vulnerability in these patients and to guide therapy. After S1P, patients are at high risk of inadequate organ

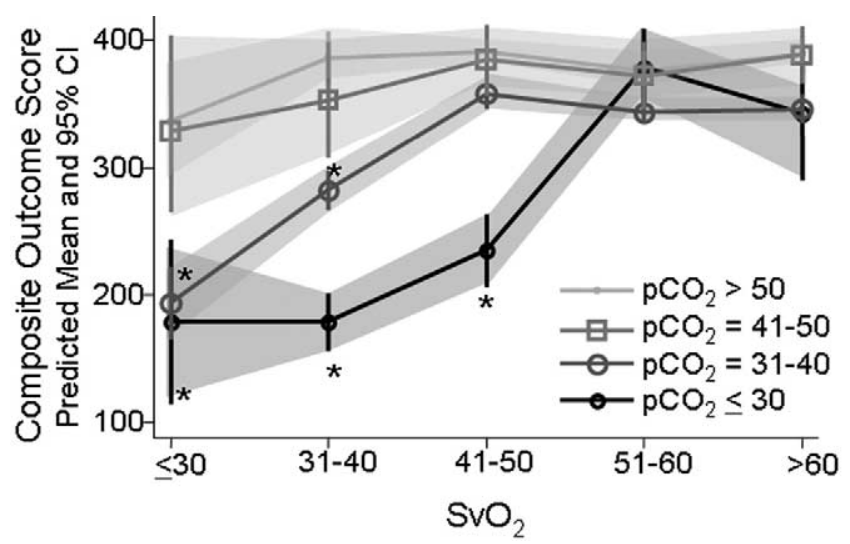

Figure 5. The interaction between postoperative $\mathrm{PaCO}_{2}$ and systemic venous oxygen saturation $\left(\mathrm{SvO}_{2}\right)$ is shown in a predictive model. Patients with lower postoperative $\mathrm{PaCO}_{2}$ had poorer outcome at lower systemic venous oxygen saturation compared with that of patients with higher $\mathrm{PaCO}_{2}{ }^{*} P<.05$, analysis of variance). Adjustment for other parameters did not change the main or interaction model effects but increased the power (from $R^{2}=\mathbf{0 . 5 2}$ to 0.64$)$. $\mathrm{Cl}$, Confidence interval. 
oxygen delivery and low $\mathrm{SvO}_{2}$ because of the superimposition of low $\mathrm{SaO}_{2}$, low systemic blood flow, and increased oxygen consumption. ${ }^{16,18}$ However, hypoxic-ischemic organ injury can result from inadequate oxygen delivery from a wide range of conditions, and we believe the relationship between $\mathrm{SvO}_{2}$ and neurodevelopmental outcome is generalizable to many high-risk populations.

In this relatively small sample, the effect of prolonged DHCA was highly collinear with mild hypocapnia, such that each term had univariate significance, but neither added power to the multivariate model. This finding makes physiologic sense in that prolonged DHCA causes prolonged impairment in cerebrovascular resistance, such that oxygen uptake and carbon dioxide production from the brain are reduced after $\mathrm{CPB} .{ }^{27}$ The data also support the speculation that a hypercapnic management strategy might improve cerebral blood flow after DHCA through reduction of cerebrovascular resistance. ${ }^{17,28}$ The break point for poorer outcome in our sample was DHCA time of greater than 60 minutes compared with the 45-minute break point from the Boston Circulatory Arrest Study. ${ }^{9}$ Our CPB strategy maintained a higher $\mathrm{PCO}_{2}$ and hemoglobin concentration than that in the Boston Circulatory Arrest Study analysis. Strategies that include a higher hemoglobin concentration ${ }^{10}$ and a higher $\mathrm{PaCO}_{2}{ }^{11}$ have been shown to improve outcome from DHCA, and thus our data are consistent with a variable dose-dependent injury related to DHCA, ${ }^{9,22,29}$ which can be affected by parameters related to cerebral oxygen delivery, such as $\mathrm{PaCO}_{2}$ and hemoglobin concentration.

In patients with parallel circulation, reduction in systemic vascular resistance can improve systemic flow by reducing and stabilizing the pulmonary/systemic flow ratio. ${ }^{30,31}$ In patients with limited cardiac output, reduction in systemic vascular resistance might divert blood flow away from the cerebral circulation. ${ }^{17,32}$ Theoretic objections to the use of afterload reduction in this patient population stem partly from this concern. ${ }^{33}$ In this study we found no evidence that the use of phenoxybenzamine impaired neurologic outcome.

The postoperative parameter most strongly related to outcome was $\mathrm{SvO}_{2}$. Because $\mathrm{SvO}_{2}$ is the flow-weighted average of regional venous saturations and because the cerebral blood contributes significantly to SVC venous blood in the resting and sedated patient, $\mathrm{SvO}_{2}$ will be strongly influenced by cerebral oxygen economy. ${ }^{15,34}$ The $\mathrm{SvO}_{2}$ might thus be closely related to whole-brain oxygen saturation in this analysis, and other measures of brain oxygen status, such as NIRS, might more directly reflect conditions of cerebral hypoxia related to adverse outcome. ${ }^{15,24,35,36}$

The hemodynamic vulnerability detected by decreased postoperative $\mathrm{SvO}_{2}$ reflects impaired oxygen delivery to metabolism balance. This impairment of oxygen economy in the early postoperative period was related to later neurocognitive disability, presumably through the development of hypoxic brain injury. Although low $\mathrm{SvO}_{2}$ tended to improve over the first 48 postoperative hours, the underlying circulatory vulnerability might persist, and those patients demonstrating late outcome impairment might have recurrent hypoxic injury beyond the acute perioperative period. ${ }^{5}$ Strategies to improve $\mathrm{SvO}_{2}$ and brain oxygenation in the perioperative period and beyond are likely to reduce the occurrence of hypoxic brain injury in high-risk patient populations.

\section{References}

1. Mahle WT, Wernovsky G. Neurodevelopmental outcomes in hypoplastic left heart syndrome. Semin Thorac Cardiovasc Surg Pediatr Card Surg Annu. 2004;7:39-47.

2. Gaynor JW, Gerdes M, Zackai EH, Bernbaum J, Wernovsky G, Clancy RR, et al. Apolipoprotein E genotype and neurodevelopmental sequelae of infant cardiac surgery. J Thorac Cardiovasc Surg. 2003; 126:1736-45.

3. Limperopoulos C, Majnemer A, Shevell MI, Rohlicek C, Rosenblatt B, Tchervenkov C, et al. Predictors of developmental disabilities after open heart surgery in young children with congenital heart defects. J Pediatr. 2002;141:51-8.

4. Fallon P, Aparicio JM, Elliott MJ, Kirkham FJ. Incidence of neurological complications of surgery for congenital heart disease. Arch Dis Child. 1995;72:418-22.

5. Wernovsky G, Shillingford AJ, Gaynor JW. Central nervous system outcomes in children with complex congenital heart disease. Curr Opin Cardiol. 2005;20:94-9.

6. Mahle WT, Tavani F, Zimmerman RA, Nicolson SC, Galli KK, Gaynor JW, et al. An MRI study of neurological injury before and after congenital heart surgery. Circulation. 2002;106(suppl I):I109-14.

7. du Plessis AJ. Cerebral hemodynamics and metabolism during infant cardiac surgery. Mechanisms of injury and strategies for protection. J Child Neurol. 1997;12:285-300.

8. Trittenwein G, Nardi A, Pansi H, Golej J, Burda G, Hermon M, et al. Early postoperative prediction of cerebral damage after pediatric cardiac surgery. Ann Thorac Surg. 2003;76:576-80.

9. Wypij D, Newburger JW, Rappaport LA, duPlessis AJ, Jonas RA, Wernovsky G, et al. The effect of duration of deep hypothermic circulatory arrest in infant heart surgery on late neurodevelopment: the Boston Circulatory Arrest Trial. J Thorac Cardiovasc Surg. 2003;126: 1397-403.

10. Jonas RA, Wypij D, Roth SJ, Bellinger DC, Visconti KJ, du Plessis AJ, et al. The influence of hemodilution on outcome after hypothermic cardiopulmonary bypass: results of a randomized trial in infants. J Thorac Cardiovasc Surg. 2003;126:1765-74.

11. Bellinger DC, Wypij D, du Plessis AJ, Rappaport LA, Riviello J, Jonas RA, et al. Developmental and neurologic effects of alpha-stat versus pH-stat strategies for deep hypothermic cardiopulmonary bypass in infants. J Thorac Cardiovasc Surg. 2001;121:374-83.

12. Priestley MA, Golden JA, O'Hara IB, McCann J, Kurth CD. Comparison of neurologic outcome after deep hypothermic circulatory arrest with alpha-stat and $\mathrm{pH}$-stat cardiopulmonary bypass in newborn pigs. J Thorac Cardiovasc Surg. 2001;121:336-43.

13. du Plessis AJ. Neurologic complications of cardiac disease in the newborn. Clin Perinatol. 1997;24:807-26.

14. Mahle WT, Lundine K, Kanter KR, Forbess JM, Kirshbom P, Tosone $\mathrm{SR}$, et al. The short term effects of cardiopulmonary bypass on neurologic function in children and young adults. Eur J Cardiothorac Surg. 2004;26:920-5.

15. Hoffman GM. Detection and prevention of neurologic injury inn the intensive care unit. Cardiol Young. 2005;15(suppl 1):149-53. 
16. Tweddell JS, Hoffman GM, Fedderly RT, Ghanayem NS, Kampine JM, Berger S, et al. Patients at risk for low systemic oxygen delivery after the Norwood procedure. Ann Thorac Surg. 2000;69:1893-9.

17. Hoffman GM, Stuth EA, Jaquiss RD, Vanderwal PL, Staudt SR, Troshynski TJ, et al. Changes in cerebral and somatic oxygenation during stage 1 palliation of hypoplastic left heart syndrome using continuous regional cerebral perfusion. J Thorac Cardiovasc Surg. 2004;127:223-33.

18. Hoffman GM, Ghanayem NS, Kampine JM, Berger S, Mussatto KA, Litwin SB, et al. Venous saturation and the anaerobic threshold in neonates after the Norwood procedure for hypoplastic left heart syndrome. Ann Thorac Surg. 2000;70:1515-21.

19. Kern FH, Ungerleider RM, Schulman SR, Meliones JN, Schell RM, Baldwin B, et al. Comparing two strategies of cardiopulmonary bypass cooling on jugular venous oxygen saturation in neonates and infants. Ann Thorac Surg. 1995;60:1198-202.

20. Skaryak LA, Chai PJ, Kern FH, Greeley WJ, Ungerleider RM. Blood gas management and degree of cooling: effects on cerebral metabolism before and after circulatory arrest. J Thorac Cardiovasc Surg. 1995; 110:1649-57.

21. Tweddell JS, Hoffman GM, Mussatto KA, Fedderly RT, Berger S, Jaquiss RD, et al. Improved survival of patients undergoing palliation of hypoplastic left heart syndrome: lessons learned from 115 consecutive patients. Circulation. 2002;106(suppl I):I82-9.

22. Bellinger DC, Jonas RA, Rappaport LA, Wypij D, Wernovsky G, Kuban KC, et al. Developmental and neurologic status of children after heart surgery with hypothermic circulatory arrest or low-flow cardiopulmonary bypass. $N$ Engl J Med. 1995;332:549-55.

23. Mahle WT, Wernovsky G. Long-term developmental outcome of children with complex congenital heart disease. Clin Perinatol. 2001; 28:235-47.

24. Austin EH 3rd, Edmonds HL Jr, Auden SM, Seremet V, Niznik G, Sehic A, et al. Benefit of neurophysiologic monitoring for pediatric cardiac surgery. J Thorac Cardiovasc Surg. 1997;114:707-17.

25. Galli KK, Zimmerman RA, Jarvik GP, Wernovsky G, Kuypers MK, Clancy RR, et al. Periventricular leukomalacia is common after neonatal cardiac surgery. J Thorac Cardiovasc Surg. 2004;127:692-704.

26. Ungerleider RM, Shen I, Yeh T, Schultz J, Butler R, Silberbach M, et al. Routine mechanical ventricular assist following the Norwood procedure-improved neurologic outcome and excellent hospital survival. Ann Thorac Surg. 2004;77:18-22.
27. Greeley WJ, Kern FH, Meliones JN, Ungerleider RM. Effect of deep hypothermia and circulatory arrest on cerebral blood flow and metabolism. Ann Thorac Surg. 1993;56:1464-6.

28. Sakamoto T, Kurosawa H, Shin'oka T, Aoki M, Isomatsu Y. The influence of $\mathrm{pH}$ strategy on cerebral and collateral circulation during hypothermic cardiopulmonary bypass in cyanotic patients with heart disease: results of a randomized trial and real-time monitoring. $J$ Thorac Cardiovasc Surg. 2004;127:12-9.

29. Ungerleider RM, Shen I. Optimizing response of the neonate and infant to cardiopulmonary bypass. Semin Thorac Cardiovasc Surg Pediatr Card Surg Annu. 2003;6:140-6.

30. Tweddell JS, Hoffman GM, Fedderly RT, Berger S, Thomas JP Jr, Ghanayem NS, et al. Phenoxybenzamine improves systemic oxygen delivery after the Norwood procedure. Ann Thorac Surg. 1999;67: 161-8.

31. Hoffman GM, Tweddell JS, Ghanayem NS, Mussatto KA, Stuth EA, Jaquis RD, et al. Alteration of the critical arteriovenous oxygen saturation relationship by sustained afterload reduction after the Norwood procedure. J Thorac Cardiovasc Surg. 2004;127:738-45.

32. Hoffman GM, Ghanayem NS, Tweddell JS. Noninvasive assessment of cardiac output. Semin Thorac Cardiovasc Surg Pediatr Card Surg Аппи. 2005;8:12-21.

33. Wernovsky G. In discussion of: Hoffman GM, Stuth EA, Jaquiss RD, Vanderwal PL, Staudt SR, Troshynski TJ, et al. Changes in cerebral and somatic oxygenation during stage 1 palliation of hypoplastic left heart syndrome using continuous regional cerebral perfusion. J Thorac Cardiovasc Surg. 2004;127:223-33.

34. Weiss M, Dullenkopf A, Kolarova A, Schulz G, Frey B, Baenziger O. Near-infrared spectroscopic cerebral oxygenation reading in neonates and infants is associated with central venous oxygen saturation. Paediatr Anaesth. 2005;15:102-9.

35. Abdul-Khaliq H, Schubert S, Troitzsch D, Huebler M, Boettcher W, Baur MO, et al. Dynamic changes in cerebral oxygenation related to deep hypothermia and circulatory arrest evaluated by near-infrared spectroscopy. Acta Anaesthesiol Scand. 2001;45:696-701.

36. Abdul-Khaliq H, Troitzsch D, Schubert S, Wehsack A, Bottcher W, Gutsch E, et al. Cerebral oxygen monitoring during neonatal cardiopulmonary bypass and deep hypothermic circulatory arrest. Thorac Cardiovasc Surg. 2002;50:77-81. 